Int. J. Electrochem. Sci., 15 (2020) $8743-8760$

\title{
Electrochemical Hydrogenation of Alpha Methyl Styrene to Cumene
}

\author{
Debalina Dasgupta ${ }^{1}$, Kanchan Mondal $^{2}$, Gautham Jegadeesan ${ }^{3}$,Shashi Lalvanit,* \\ ${ }^{1}$ National Energy Technology Laboratory, Department of Energy, Pittsburgh, PA 15129 \\ ${ }^{2}$ Mechanical Engineering and Energy Processes, Southern Illinois University, Carbondale, IL 62901 \\ ${ }^{3}$ SASTRA University, Thanjavur, Tamal Nadu, India \\ ${ }^{4}$ Chemical, Paper and Biomedical Engineering, Miami University, Oxford, OH 45069 \\ *E-mail: lalvansb@muohio.edu
}

doi: $10.20964 / 2020.09 .10$

Received: 9 January 2020 / Accepted: 17 March 2020 / Published: 10 August 2020

\begin{abstract}
A new hydrogenation process for atmospheric pressure conversion of alpha methyl styrene (AMS) to cumene is described. Formate ion is provided as a proton transfer agent in the reaction which involves AMS and water in the presence of a palladium catalyst. The bicarbonate ion, a product of the reaction is continuously reduced at the cathode of an electrochemical reactor to regenerate the formate. The influence of the emulsifying agent, formate concentration, applied potential and current density, the solution $\mathrm{pH}$ and temperature on the rate of AMS conversion is determined. Up to $96 \%$ AMS conversion was obtained at $60{ }^{\circ} \mathrm{C}$.
\end{abstract}

Keywords: mediated electrochemical reduction, alpha methylstyrene, cumene, bicarbonate-formate redox

\section{$\underline{\text { FULL TEXT }}$}

(C) 2020 The Authors. Published by ESG (www.electrochemsci.org). This article is an open access article distributed under the terms and conditions of the Creative Commons Attribution license (http://creativecommons.org/licenses/by/4.0/). 